ESRI

SURVEY AND STATISTICAL REPORT SERIES NUMBER 93 JULY 2020

\section{DIFFERENCES IN RISK OF SEVERE OUTCOMES FROM COVID-19 ACROSS OCCUPATIONS IN IRELAND}

BRENDAN WALSH, PAUL REDMOND AND BARRA ROANTREE

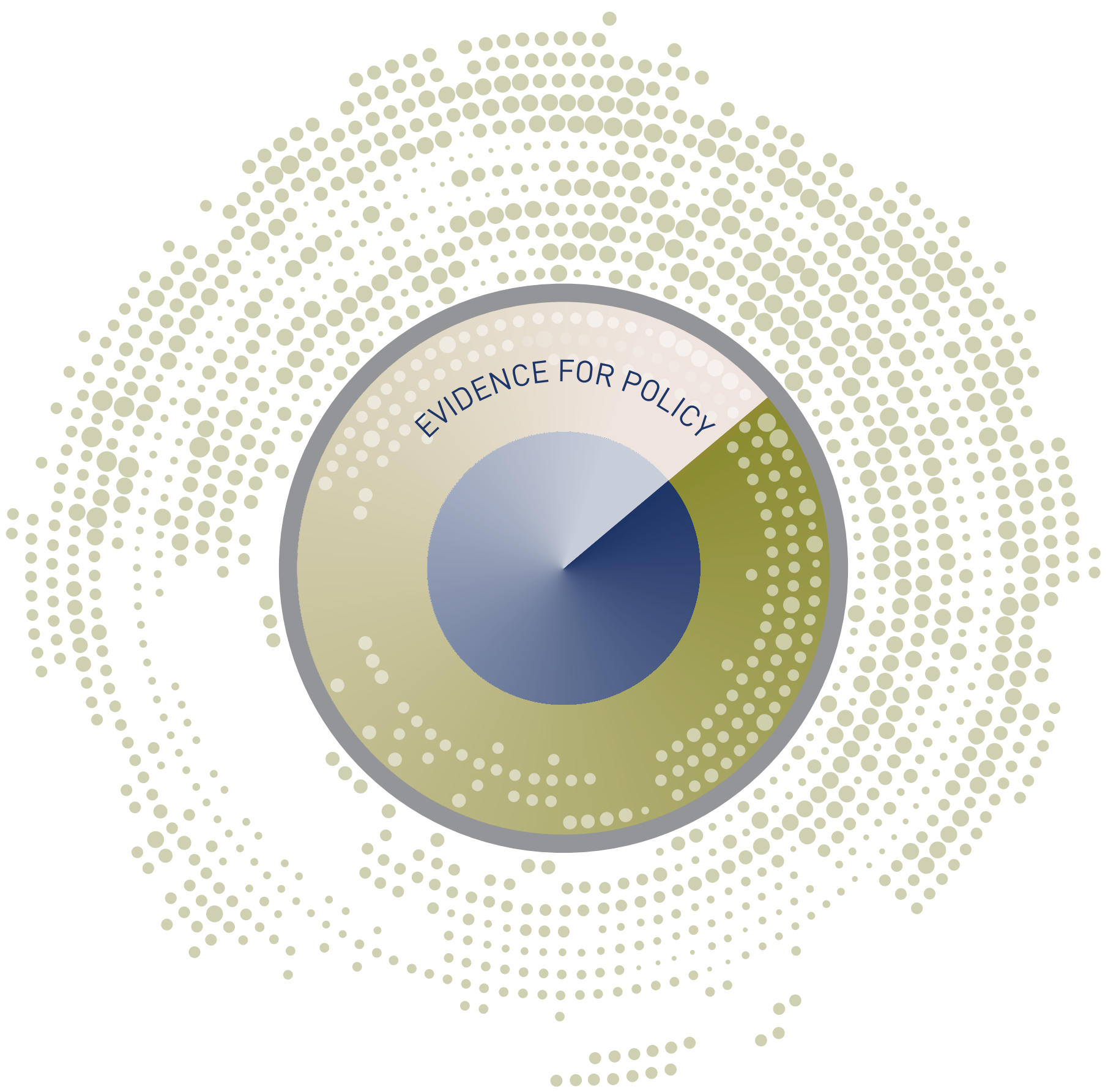




\title{
DIFFERENCES IN RISK OF SEVERE OUTCOMES FROM COVID-19 ACROSS OCCUPATIONS IN IRELAND
}

\author{
Brendan Walsh \\ Paul Redmond \\ Barra Roantree
}

\section{July 2020}

Available to download from www.esri.ie

The Economic and Social Research Institute Whitaker Square, Sir John Rogerson's Quay, Dublin 2

ISBN 978-0-7070-536-2

https://doi.org/10.26504/sustat93

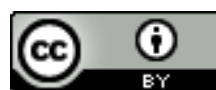

This Open Access work is licensed under a Creative Commons Attribution 4.0 International License (https://creativecommons.org/licenses/by/4.0/), which permits unrestricted use, distribution, and reproduction in any medium, provided the original work is properly credited. 


\section{ABOUT THE ESRI}

The mission of the Economic and Social Research Institute is to advance evidencebased policymaking that supports economic sustainability and social progress in Ireland. ESRI researchers apply the highest standards of academic excellence to challenges facing policymakers, focusing on 12 areas of critical importance to 21st Century Ireland.

The Institute was founded in 1960 by a group of senior civil servants led by Dr T. K. Whitaker, who identified the need for independent and in-depth research analysis to provide a robust evidence base for policymaking in Ireland.

Since then, the Institute has remained committed to independent research and its work is free of any expressed ideology or political position. The Institute publishes all research reaching the appropriate academic standard, irrespective of its findings or who funds the research.

The quality of its research output is guaranteed by a rigorous peer review process. ESRI researchers are experts in their fields and are committed to producing work that meets the highest academic standards and practices.

The work of the Institute is disseminated widely in books, journal articles and reports. ESRI publications are available to download, free of charge, from its website. Additionally, ESRI staff communicate research findings at regular conferences and seminars.

The ESRI is a company limited by guarantee, answerable to its members and governed by a Council, comprising 14 members who represent a cross-section of ESRI members from academia, civil services, state agencies, businesses and civil society. The Institute receives an annual grant-in-aid from the Department of Public Expenditure and Reform to support the scientific and public interest elements of the Institute's activities; the grant accounted for an average of 30 per cent of the Institute's income over the lifetime of the last Research Strategy. The remaining funding comes from research programmes supported by government departments and agencies, public bodies and competitive research programmes.

Further information is available at www.esri.ie 


\section{THE AUTHORS}

Brendan Walsh, Paul Redmond and Barra Roantree are Research Officers at the ESRI and Adjunct Assistant Professors at Trinity College Dublin.

\section{ACKNOWLEDGEMENTS}

The authors would like to thank the Department of Health for providing the Healthy Ireland Survey data and the Central Statistics Office for providing the Labour Force Survey data used in this paper. The authors thank Sheona Gilsenan, Department of Health, and Dr Anne Nolan, Dr Bertrand Maître and Dr Conor Keegan, ESRI, for their helpful comments.

This report has been accepted for publication by the Institute, which does not itself take institutional policy positions. The report has been peer-reviewed prior to publication. The authors are solely responsible for the content and the views expressed. 



\section{TABLE OF CONTENTS}

\begin{tabular}{|c|c|}
\hline 1. & INTRODUCTION ... \\
\hline 2. & OCCUPATIONS AND COVID-19 RISK PROFILES ......................... \\
\hline 2.1 & Chronic Illness... \\
\hline 2.2 & Age........ \\
\hline 2.3 & Deprivation.................................. \\
\hline 3. & DATA .. \\
\hline 3.1 & 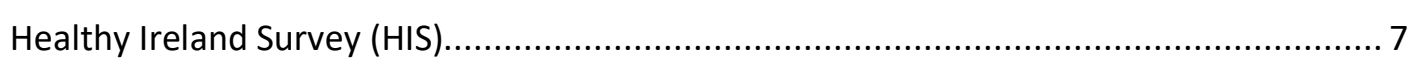 \\
\hline 3.2 & Labour Force Survey (LFS) ... \\
\hline 4. & RESULTS.................................... \\
\hline 4.1 & 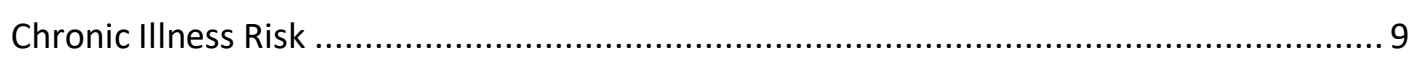 \\
\hline 4.2 & Age Risk .................................. \\
\hline 4.3 & Deprivation Risk \\
\hline 4.4 & Exposure and Mortality Risk across Occupations..... \\
\hline \multicolumn{2}{|r|}{ 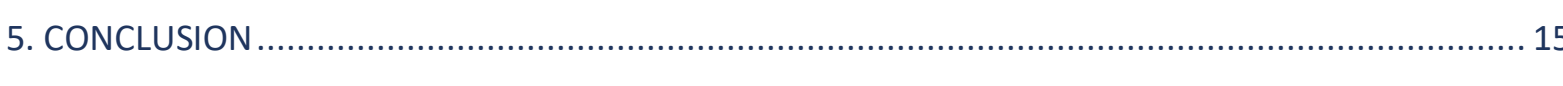 } \\
\hline REFE & NCES \\
\hline
\end{tabular}




\section{LIST OF TABLES}

Table 1 Underlying health conditions in confirmed cases (by place of treatment) of, and deaths from,

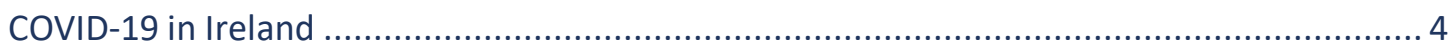

Table 2 Occupations with highest COVID-19-vulnerable chronic illness rates............................... 10

Table 3 Occupations with largest share of workers aged 50 years and older .............................. 11

Table 4 Occupations with highest share of workers living in most deprived quantile ................... 12

Table 5 Occupations identified to be at highest risk from COVID-19 ......................................... 14

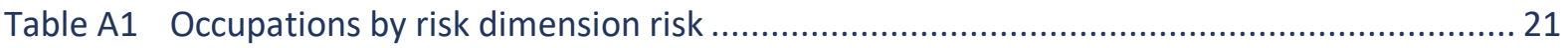

\section{LIST OF FIGURES}

Figure 1 Number of confirmed COVID-19 cases, hospitalisations and deaths, by age group ........... 5

Figure 2 Distribution of COVID-19 cases per 100,000 population by deprivation quantile .............. 6 


\section{SUMMARY POINTS}

- There are large differences in the potential risks of severe outcomes from COVID-19 to workers across occupations in Ireland, relating to underlying health conditions, age and deprivation.

- Over 15 per cent of workers have a COVID-19-vulnerable chronic illness. The highest rates of chronic illness are among housekeeping and related services (34\%), road transport drivers (26\%), and caring professions (e.g. care workers) (22\%).

- There are also differences in the proportion of older workers across sectors. Agricultural and related trades (e.g. farmers), housekeeping and related services, and road transport drivers contain the largest share of workers aged above 50, at 63, 53 and 47 per cent respectively.

- Many essential workers, especially those in elementary occupations, are more likely to live in deprived areas than others. Most notable are elementary cleaning (39\%), security (30\%) and process plant workers (25\%). Care workers, housekeeping and related services, and road transport drivers also disproportionately live in areas of high deprivation.

- Workers in essential occupations continued working throughout the crisis. In addition to facing greater exposure to COVID-19, many of these essential workers are older, live in more deprived areas, and have greater rates of COVID-19-vulnerable chronic illness. This may help explain why workers in these occupations have been shown to have higher mortality rates in other countries.

- The COVID-19 crisis has shown in greater detail the socio-economic disparities that exist between occupations in Ireland, and that often it is those occupations most essential to the running of society and the economy that tend to have workers who are in lowerpaying and less secure professions. Yet these workers have been at the frontline of the COVID-19 crisis, a frontline that spans both healthcare and non-healthcare workers. 



\section{INTRODUCTION}

Following the onset of COVID-19 in Ireland, the Government identified those sectors and occupations seen as essential to allow for the functioning of society, the economy and the healthcare system (Department of the Taoiseach, 2020). Some essential workers may have been able to work remotely, but this was not possible for most workers (Crowley and Doran, 2020). For example, health and care workers, public transport workers, and those involved in food production and supply continued to work on the frontline. It is estimated that approximately 22 per cent of workers both in Ireland and the UK are essential employees (Farquharson, Rasul et al., 2020; Redmond and McGuinness, 2020).

The inability of many workers in these essential occupations to work from home has meant that some faced a disproportionate risk of contracting COVID-19. The Central Statistics Office (CSO) found large differences in risk of exposure to COVID19 across occupations, due to differences in working in proximity to others in the workplace and increased exposure to disease more generally (CSO, 2020a). Healthcare workers were identified to be of particular high risk. As of $27 \mathrm{June},{ }^{1} 32$ per cent of confirmed COVID-19 cases $(8,260)$ were among healthcare workers (HPSC, 2020a). Evidence shows that 3.7 per cent of healthcare worker confirmed cases were hospitalised, which constituted 9.3 per cent of all hospitalisations and 20.9 per cent of hospitalisations for ages 15 to 64 up to that point (HPSC, 2020a).

In this paper we identify those occupations with workers that have the highest susceptibility to poor health outcomes from COVID-19, such as more severe illness, greater probability of hospital admission, and high mortality risk. We show that many essential occupations face greater underlying risks if they contract COVID19 , as they contain a large share of workers that have a COVID-19-vulnerable chronic illness, are aged 50 years and older, or live in a deprived area. All three of these factors have been linked to higher rates of mortality and severe health outcomes from COVID-19. The European Centre for Disease Prevention and Control (ECDC), for example, states that "the risk of severe disease associated with COVID-19 for people in the EU/EEA and the UK is currently considered moderate for the general population and very high for older adults and individuals with chronic underlying conditions" (ECDC, 2020). Other factors, including access to healthcare (Ji, Ma et al., 2020) and deprivation (ONS, 2020), have been shown to affect health outcomes from COVID-19.

The Return to Work Safely Protocol (Department of Business, 2020), a collaborative

${ }^{1}$ Throughout this paper we have used the most up-to-date information available at the time of writing. However, there may be some discrepancies across topics and tables/figures on the date of the most recent data available. 
effort by the Health and Safety Authority (HSA), the Health Services Executive (HSE), the Department of Health, and the Department of Business, Enterprise and Innovation, has outlined measures to support employers and workers in preventing the spread of COVID-19 in the workplace as the economy reopens. ${ }^{2}$ One feature of this protocol guidance to employers is that, if an at-risk worker cannot work from home, supports such as two-metre social distancing should be maintained. However, this is not feasible in many workplaces. Identifying those occupations with workers most prone to severe health outcomes from COVID-19, due to, for example, high prevalence of underlying conditions, could aid in efforts to equip the most vulnerable workers with proactive measures (e.g. personal protective equipment, protective barriers) to mitigate the risk of contracting COVID-19.

This paper proceeds as follows. In Section 2 we outline the three dimensions of underlying risk we consider: COVID-19-vulnerable chronic conditions, age, and living in an area of deprivation. Section 3 describes the data we use to examine these dimensions, while Section 4 presents our results. Section 5 concludes with a discussion of their implications for policy.

\footnotetext{
${ }^{2}$ The HSA is carrying out inspections to promote compliance with the safety protocols.
} 


\section{OCCUPATIONS AND COVID-19 RISK PROFILES}

In this paper, we draw on several sources to identify occupations in Ireland that are likely to face the greatest risk from COVID-19. We concentrate on individuals aged 15 to 70 in employment, using the Healthy Ireland Survey (HIS) and Labour Force Survey (LFS). Both the HIS and LFS data contain employment and occupation information at the Standard Occupational Classification ${ }^{3}$ (SOC) four-digit occupation level. However, at this level of disaggregation, some occupations contain too few observations to perform meaningful analysis. We thus focus on the three-digit SOC occupation level, which allows for detailed analysis of individual occupations while preserving sufficient sample size for results to be reliable.

To show the structure of the SOC2010 occupation codes and the difference between three- and four-digit codes, we can refer to an example. The broadest SOC occupation category is at the one-digit level. For example, SOC code 6 captures caring, leisure and other service occupations. SOC code 6 can be subdivided into two two-digit occupation codes: SOC code 61 is caring personal service occupations and SOC code 62 is leisure, travel and related personal service occupations. The next level of detail is the three-digit level. For example, the two-digit SOC occupation 61 (caring personal service occupations) is further disaggregated into the following three-digit occupations: 612 (childcare and related personal services); 613 (animal care and control services), and 614 (caring personal services). It is these three-digit occupations that we work with. As mentioned, there is a most granular, four-digit level. For example, occupation 614 (caring personal services) consists of the following: 6141 (nursing auxiliaries and assistants); 6142 (ambulance staff excluding paramedics); 6143 (dental nurses); 6144 (houseparents and residential wardens); 6145 (care workers and home carers); 6146 (senior care workers); 6147 (care escorts) and 6148 (undertakers). However, the four-digit occupations often contain too few observations to be included in the analysis. In the example shown above, codes $6142,6144,6146$ and 6148 are very sparsely populated in the data. Therefore, the three-digit occupation codes are optimal for this analysis.

We provide a profile of occupations across three risk dimensions that have been identified in the literature to be most vulnerable to more severe health outcomes from COVID-19: underlying health conditions, age and deprivation.

\footnotetext{
${ }^{3}$ The Standard Occupational Classification (SOC) is a standardised way to classify workers into occupational categories, used in Ireland and internationally.
} 


\subsection{CHRONIC ILLNESS}

First, we use the HIS data to analyse occupations with the highest prevalence of chronic illnesses that may lead to worse COVID-19 health outcomes. There is clear evidence that individuals with particular underlying health conditions have higher rates of hospitalisation, intensive-care unit (ICU) use, and mortality from COVID19. Table 1 highlights the most commonly reported underlying health conditions among COVID-19 confirmed cases and deaths in Ireland. Chronic heart disease, chronic respiratory disease, diabetes, chronic neurological disease (e.g. Alzheimer's disease, dementia, Parkinson's disease), cancer, chronic kidney disease and asthma were the most commonly reported chronic conditions, and many cases had multiple underlying conditions (HPSC, 2020b). Using those conditions most common among COVID-19 cases, we examine whether these diseases (which we term 'COVID-19-vulnerable chronic illness') are more prevalent among certain occupations in Ireland. OF, AND DEATHS FROM, COVID-19 IN IRELAND

\begin{tabular}{|l|c|c|c|c|c|}
\hline & \multicolumn{4}{|c|}{ Confirmed Cases } & Deaths \\
\hline & Community & Hospital & ICU & All Settings & All Settings \\
\hline Chronic Heart Disease & $10.4 \%$ & $35.2 \%$ & $49.8 \%$ & $14.1 \%$ & $42.5 \%$ \\
\hline Chronic Respiratory Disease & $9.1 \%$ & $19.8 \%$ & $24.3 \%$ & $10.7 \%$ & $17.1 \%$ \\
\hline Diabetes & $4.6 \%$ & $16.0 \%$ & $23.8 \%$ & $6.2 \%$ & $14.6 \%$ \\
\hline Chronic Neurological Disease & $4.9 \%$ & $12.3 \%$ & $3.7 \%$ & $6.0 \%$ & $31.4 \%$ \\
\hline Cancer & $2.3 \%$ & $12.5 \%$ & $11.5 \%$ & $3.8 \%$ & $15.1 \%$ \\
\hline Chronic Kidney Disease & $1.6 \%$ & $9.2 \%$ & $7.8 \%$ & $2.7 \%$ & - \\
\hline Asthma (Req. Medication) & $1.9 \%$ & $5.5 \%$ & $11.8 \%$ & $2.4 \%$ & \\
\hline
\end{tabular}

Source: HPSC Computerised Infectious Disease Reporting (CIDR) dataset. Data correct as of 24/06/2020.

Notes: Information is available on underlying health conditions for 19,038 confirmed cases of COVID-19, and 1,406 deaths from COVID-19, for notifications up to and including 24/06/2020. These data do not represent all confirmed COVID19 cases.

Cases may have multiple underlying chronic conditions listed.

\subsection{AGE}

Second, we look at age-based risk to COVID-19 across occupations. While there is a relationship between chronic illness rates and age, increased age itself may also increase susceptibility to severe COVID-19 outcomes. Previous research has shown that older people in Ireland have much higher rates of frailty (Roe, Normand et al., 2017), which may result in more severe outcomes, such as hospitalisation or death, if they contract COVID-19. In general, chronic illness is also more debilitating at older ages. We use the Irish LFS to examine the age profile of all occupations in Ireland, identifying those with the greatest percentage of older workers (characterised as those aged 50+). The rationale for this is based on evidence of an 
increased number of COVID-19 hospitalisations and deaths at older ages. The age composition of some occupations may therefore result in greater susceptibility to severe consequences of COVID-19. Figure 1 shows that over 54 per cent of confirmed COVID-19 cases involving hospitalisation were aged 65 and older, while 92 per cent of confirmed COVID-19 deaths occurred among individuals aged 65 and older. The increase in deaths accelerates sharply from age 50.

FIGURE 1 NUMBER OF CONFIRMED COVID-19 CASES, HOSPITALISATIONS AND DEATHS, BY AGE GROUP

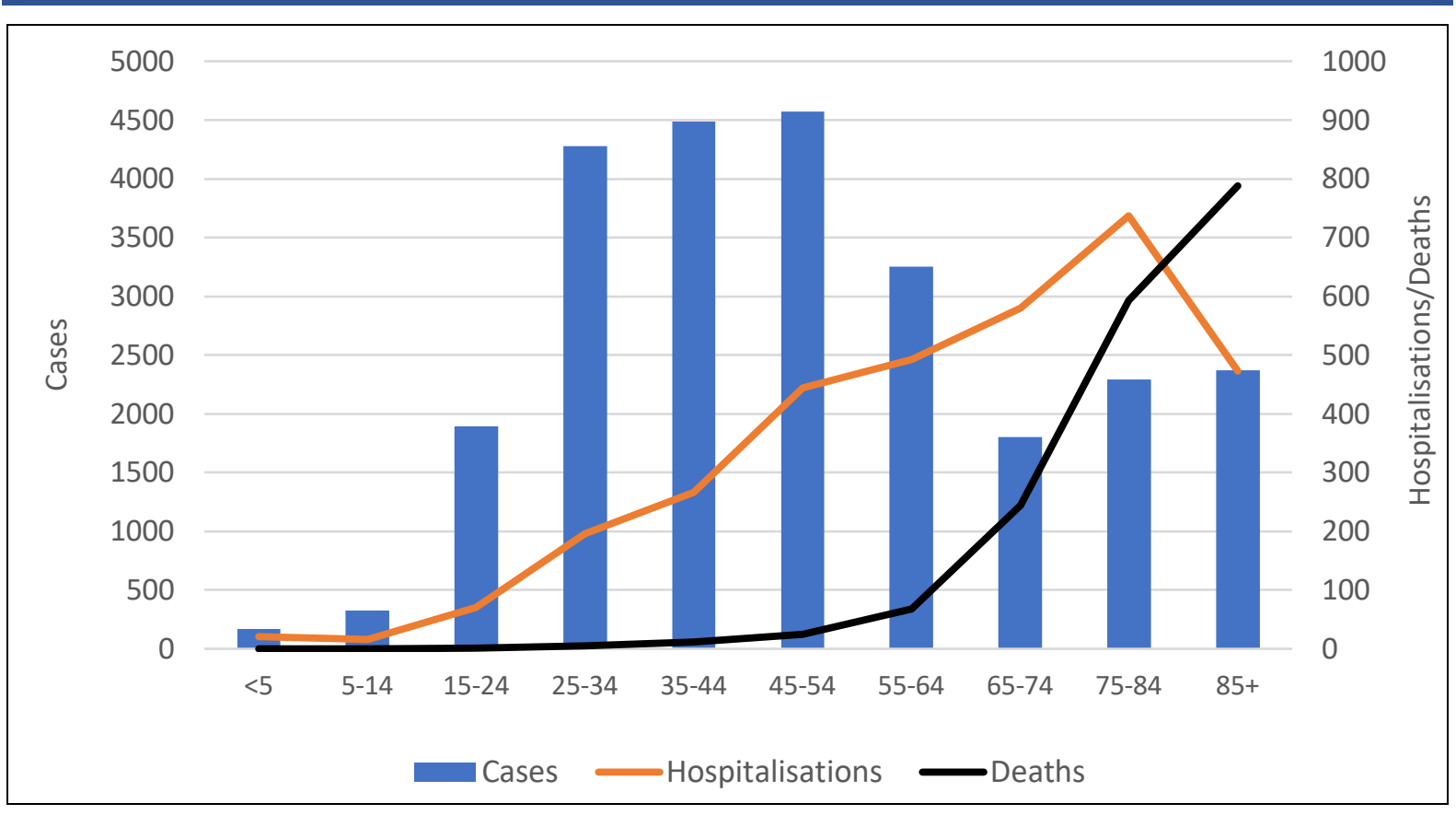

Source: HPSC Computerised Infectious Disease Reporting (CIDR) dataset. Data correct as of 29/06/2020.

\subsection{DEPRIVATION}

Third, we look at area-level deprivation across occupations. The evidence on the link between deprivation and severe COVID-19 outcomes differs across countries. There is strong evidence from some countries that those who live in more deprived areas have higher rates of COVID-19 infection rates and mortality. In England and Wales, those living in the most deprived areas have much higher rates of COVID19 incidence and mortality; COVID-19 mortality rates are 30 per cent higher in the most deprived deciles compared to the least deprived decile (ONS, 2020).

The evidence is less clear in Ireland. As shown in Figure 2, data from the CSO finds COVID-19 confirmed case rates were higher in the least deprived areas ${ }^{4}(625$ confirmed cases per 100,000$)$ as compared to the most deprived group (478

\footnotetext{
${ }^{4}$ Deprivation is based on the estimated deprivation in the Census of Population 2016 small areas using the Pobal HP Deprivation Index.
} 
confirmed cases per 100,000) (CSO, 2020b). There are three important caveats with these data. First, deprivation is based on the address of the individual, and CSO numbers are based on a 70 per cent match rate between the HPSC Computerised Infectious Disease Reporting (CIDR) dataset which records COVID19 cases and small-area information from Census 2016. An allocation process is used for the remaining 30 per cent of cases. Second, higher confirmed case rates may be a consequence of more testing in the least deprived areas. Third, these statistics include cases detected in long-term residential care (LTRC) settings (e.g. nursing homes). The small area of the LTRC centre is assigned to the residents as opposed to their native home address and may therefore not be representative of the residents' socio-economic characteristics. We therefore continue to treat deprivation as a risk factor for COVID-19 among workers due to the strong correlation found in other countries.

\section{FIGURE 2 DISTRIBUTION OF COVID-19 CASES PER 100,000 POPULATION BY DEPRIVATION QUANTILE}

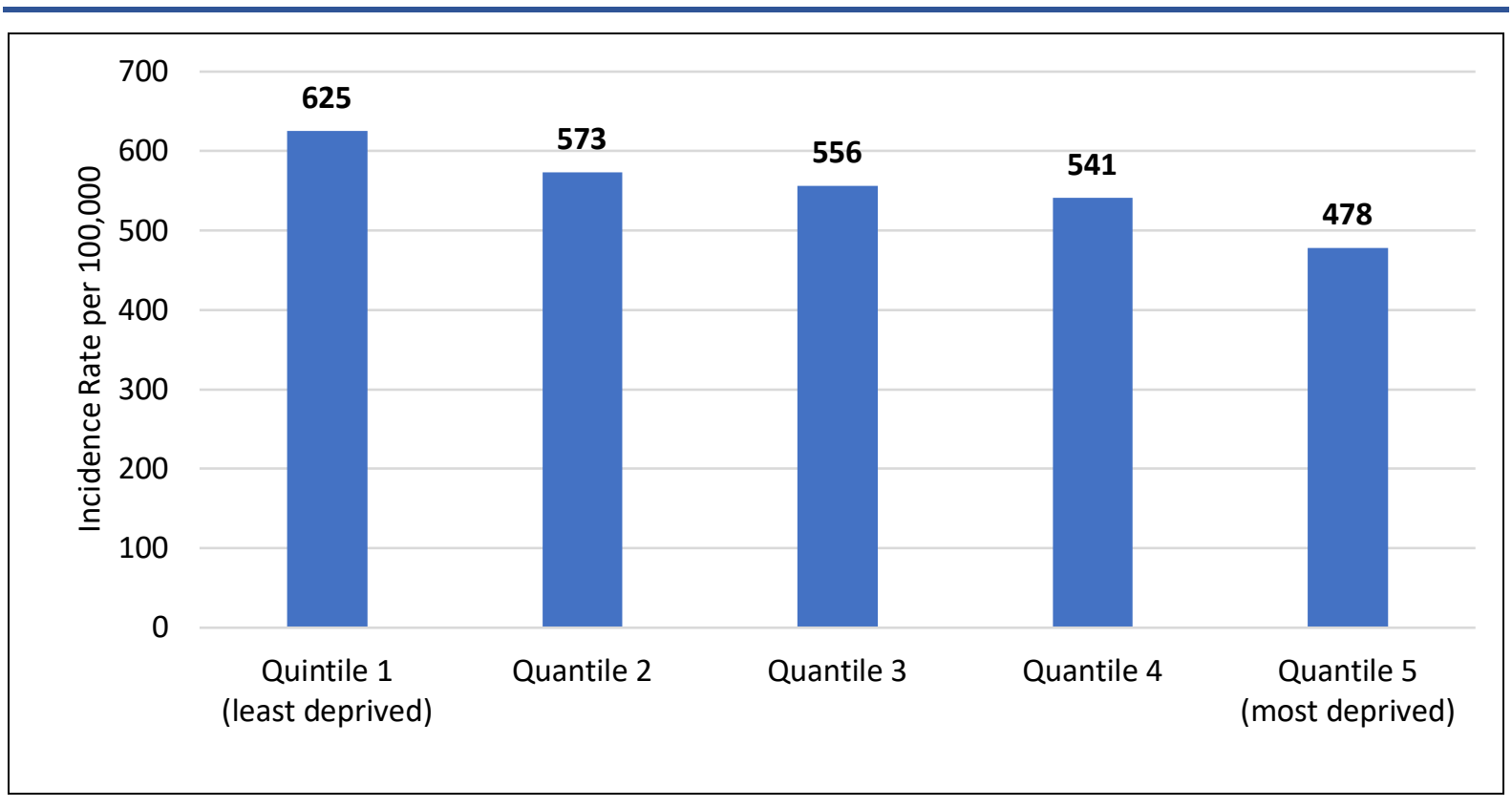

Source: HPSC Computerised Infectious Disease Reporting (CIDR) dataset and Central Statistics Office. Data correct as of 05/07/2020.

Notes: Deprivation quantiles are based on the estimated deprivation in the Census of Population 2016 small areas using the Pobal HP Deprivation Index. Long-term residential care (LTRC) residents with COVID-19 are assigned to the deprivation level of their LTRC centre. 


\section{DATA}

\subsection{HEALTHY IRELAND SURVEY (HIS)}

The HIS is a cross-sectional survey collected by the Department of Health and IPSOS MBRI annually since 2015. The HIS is administered on a face-to-face basis with a representative sample of individuals aged 15 years and older; respondents are not followed across survey waves. The HIS collects a range of health and demographic information, including the employment status and occupation of workers, using the SOC2010. Employment status and SOC2010 are captured in the first four waves, which encompass the years 2015 to 2018. Pooling information from the four waves provides us with a sample of 13,574 workers aged 15 to 70 years of age.

The HIS collects information on health conditions the respondent had in the preceding 12 months. In waves 1 and 2, a total of 16 conditions were captured, while in waves 3 and 4 a total of 25 conditions were captured. Based upon evidence on the most prevalent underlying conditions among more severe COVID-19 patients (see Table 1), we created a binary COVID-19-vulnerable chronic illness variable grouping together eight health conditions captured in HIS. Conditions included in waves 1-4 were: Asthma, Chronic Lung Disease (e.g. chronic obstructive pulmonary disease (COPD), emphysema), Diabetes, Heart Attack, and High Blood Pressure. Included in wave 1-2: Kidney Problems. Included in waves 3-4: Congestive Heart Failure, Cancer. These conditions also correspond closely to a similar analysis undertaken by Blundell et al. (2020) in the UK, and with the prevalence of COVID-19-vulnerable chronic illnesses among those aged 50 and over in the Irish Longitudinal Study on Ageing (TILDA) (Hernández, Sexton et al., 2020). While there is evidence that many older individuals who die from COVID-19 have dementia or Alzheimer's disease (Chronic Neurological Disease in Table 1) (Hennelly and Cahill, 2020), this is not the case among the working-age population that die from COVID-19. Therefore, we do not include dementia and Alzheimer's as these diseases are quite different from other diseases, in that they generally do not affect younger workers (ONS, 2020).

The HIS also includes information on the area-level deprivation for each individual. The deprivation index used in the HIS is based on the Pobal HP Deprivation Index and estimated deprivation at small-area level. The Pobal index is based on the combination of three dimensions: demographic profile (e.g. age dependency rate), social class composition (e.g. education levels), and labour-market situation (e.g. unemployment rates). In the analysis, we collapse deprivation into quantiles, and examine the proportion of the workforce in the most deprived quantile $(20 \%)$. 


\subsection{LABOUR FORCE SURVEY (LFS)}

We use the LFS to derive statistics relating to the age and household composition of workers in Ireland. The LFS is a large-scale, quarterly, nationwide survey of households in Ireland. It is used to produce official labour-force statistics, including the employment and unemployment rates. The LFS data categorise occupations based on the SOC2010 coding. This allows us to match our age, gender and household composition statistics to the corresponding health statistics from the HIS data for each occupation. To achieve sufficiently large sample sizes, we combine data from the LFS surveys from 2017 to 2019 for workers aged 15 years and older ( $99 \%$ are aged 70 years or less). For each three-digit SOC occupation, we use the LFS data to calculate the percentage of workers (both employed and selfemployed) aged over 50 years of age. We also present the number of workers in each occupation as of quarter 42019 to reflect the size of each occupation in the wider economy. 


\section{RESULTS}

In this section, we present results of the top 10 occupations (SOC 3-digit) according to our three risk dimensions (Tables 2-4). We then identify those specific occupations that may be most at risk to more severe consequences of COVID-19 based on exposure to COVID-19, potentially high mortality rates, and having high risk profiles at a more granular level (SOC 4-digit). Appendix Table A1 provides results for all occupations (SOC 3-digit) where data permits.

\subsection{CHRONIC ILLNESS RISK}

Table 2 shows the occupations that we estimate to have the highest COVID-19vulnerable chronic illness rates. Housekeeping and related services stand out as having the highest chronic illness risk, with just over a third of such workers reporting a COVID-19-vulnerable chronic disease. A quarter of the c.70,000 road transport - including large goods vehicle (LGV), van, bus and taxi - drivers also report having such diseases, as do 22 per cent of the almost 85,000 working in caring personal services (e.g. home carers, nursing home carers). A total of 22 per cent of those working as financial institution managers/directors also report having a COVID-19-vulnerable chronic illness, alongside 20 per cent of those working in public services or other associate professions. Lastly, just under a fifth of the c.120,000 people working in agriculture and related trades and elementary process plant occupations - including meat-processing - report such a condition. 


\begin{tabular}{|l|l|c|c|}
\hline SOC2010 Code & Occupation & $\begin{array}{c}\text { COVID-19- } \\
\text { vulnerable } \\
\text { chronic } \\
\text { illness }\end{array}$ & $\begin{array}{c}\text { Number of } \\
\text { workers }^{\mathbf{b}}\end{array}$ \\
\hline 623 & Housekeeping and Related Services & $33.9 \%$ & 19,810 \\
\hline 821 & Road Transport Drivers & $25.8 \%$ & 70,351 \\
\hline 116 & Managers and Directors in Transport and Logistics & $24.2 \%$ & 10,373 \\
\hline 524 & Elementary Security Occupations & $23.4 \%$ & 17,878 \\
\hline 115 & Other Skilled Trades & $22.6 \%$ & 7,929 \\
\hline 614 & Financial Institution Managers and Directors & $22.2 \%$ & 7,368 \\
\hline 356 & Caring Personal Services & $22.0 \%$ & 84,801 \\
\hline 511 & Public Services and Other Associate Professionals & $20.4 \%$ & 30,931 \\
\hline 913 & Agricultural and Related Trades & $19.5 \%$ & 110,233 \\
\hline
\end{tabular}

Sources: $\quad$ a Healthy Ireland Survey (Waves 1-4); ${ }^{b}$ Labour Force Survey: Numbers of workers estimated for quarter 4 of 2019. Notes: COVID-19-Vulnerable Chronic Illness includes Asthma, Chronic Lung Disease (e.g. COPD, emphysema), Diabetes, Heart Attack/Congestive Heart Failure, High Blood Pressure, Cancer, and Kidney Problems.

\subsection{AGE RISK}

Table 3 shows the proportion of workers aged 50 and older across occupations. The occupational group with the largest proportion of older workers is agricultural and related trades (e.g. farmers), with 63 per cent aged 50 years or above. Housekeepers and related services, and road transport drivers once more have a large percentage of older workers, at 53 and 47 per cent respectively. 


\begin{tabular}{|llcc}
\hline $\begin{array}{l}\text { SOC2010 } \\
\text { Code }\end{array}$ & Occupation & $\begin{array}{c}\text { Percentage aged } \\
\mathbf{5 0 +}\end{array}$ & $\begin{array}{c}\text { Number of } \\
\text { workers }\end{array}$ \\
\hline 511 & Agricultural and Related Trades & $62.8 \%$ & 110,233 \\
\hline 623 & Housekeeping and Related Services & $52.6 \%$ & 19,810 \\
\hline 821 & Road Transport Drivers & $47.2 \%$ & 70,351 \\
\hline 921 & Elementary Administration Occupations & $46.6 \%$ & 10,198 \\
\hline 125 & Managers and Proprietors in Other Services & $44.6 \%$ & 38,598 \\
\hline 244 & Welfare Professionals & $42.6 \%$ & 9,101 \\
\hline 118 & Health and Social Services Managers and & $40.6 \%$ & 4,451 \\
& Directors & $40.1 \%$ & 51,277 \\
\hline 411 & Administrative Occs.: Government \& Related Orgs & $38.4 \%$ & 48,247 \\
\hline 421 & Secretarial and Related Occupations & $37.6 \%$ & 53,471 \\
\hline 113 & Functional Managers and Directors & $\mathbf{2 7 . 6 \%}$ & $\mathbf{2 , 3 6 1 , 2 0 0}$ \\
\hline & All Workers & & \\
\hline Sources: & a Labour Force Survey: Numbers of workers estimated for quarter 4 of 2019. & & \\
\hline
\end{tabular}

\subsection{DEPRIVATION RISK}

Table 4 shows the proportion of workers who live in the most deprived quantile (most deprived 20\%) across occupations. Workers in elementary trades, including cleaning (39\%), construction (36\%), and security (30\%) are particularly likely to live in areas with high rates of deprivation. Housekeepers and related services (27\%), road transport drivers $(28 \%)$, and sales assistants and retail cashiers $(24 \%)$ also live in areas with high rates of deprivation. The high rates of deprivation in some occupations are notable despite workers living in less deprived areas (17 per cent of workers aged 15 to 70 live in the most deprived quantile versus 27.3 per cent of non-workers). As Appendix 4 shows, there are large differences in the percentage of workers living in deprived areas, with ranges from 0 to 39 per cent across occupations. 


\begin{tabular}{llcc} 
SOC2010 Code & Occupation & $\begin{array}{c}\text { Live in most } \\
\text { deprived } \\
\text { quantile }^{\mathbf{a}}\end{array}$ & $\begin{array}{c}\text { Number } \\
\text { of } \\
\text { workers }^{\mathbf{b}}\end{array}$ \\
\hline 923 & Elementary Cleaning Occupations & $39.4 \%$ & 45,529 \\
\hline 912 & Elementary Construction Occupations & $35.5 \%$ & 24,236 \\
\hline 924 & Elementary Security Occupations & $29.5 \%$ & 17,878 \\
\hline 814 & Construction Operatives & $28.7 \%$ & 12,205 \\
\hline 821 & Road Transport Drivers & $27.9 \%$ & 70,351 \\
\hline 614 & Caring Personal Services & $27.7 \%$ & 84,801 \\
\hline 623 & Housekeeping and Related Services & $27.0 \%$ & 19,810 \\
926 & Elementary Storage Occupations & $26.1 \%$ & 22,615 \\
\hline 913 & Elementary Process Plant Occupations & $24.7 \%$ & 11,395 \\
\hline 323 & Welfare and Housing Associate Professionals & $24.7 \%$ & 10,846 \\
\hline & All Workers & $\mathbf{1 7 . 0 \%}$ & $\mathbf{2 , 3 6 1 , 2 0 0}$
\end{tabular}

Sources: $\quad{ }^{a}$ Healthy Ireland Survey (Waves 1-4); ${ }^{b}$ Labour Force Survey: Numbers of workers estimated for quarter 4 of 2019.

\subsection{EXPOSURE AND MORTALITY RISK ACROSS OCCUPATIONS}

The results from Tables 2-4 show a number of occupations are at higher risk from COVID-19 in Ireland across more than one of the risk dimensions examined. Three occupations have higher risk across all three dimensions: housekeeping and related services, road transport drivers, and agricultural and related trades. Three further occupations - caring personal services, elementary process plant operatives, and elementary security occupations - have high risk across two dimensions. Many workers in each of these occupations are essential workers and have continued to work during the COVID-19 pandemic. Therefore, many of the occupations we have identified will have both greater likelihood of contracting COVID-19 and higher susceptibility to more severe health outcomes.

Data on severe consequences from COVID-19 (e.g. hospitalisation, mortality) by occupation do not exist for Ireland, meaning it is not possible to examine whether occupations with higher risks experience worse outcomes from the disease. However, the CSO (CSO 2020a) has applied the US Department of Labor, Employment and Training Administration's Occupational Information Network (O*NET) data, which examines overall exposure to disease based on the features of a worker's job, to occupations in Ireland, to identify those occupations with higher potential risk of exposure to COVID-19. Similar approaches have been undertaken internationally (Baker, Peckham et al., 2020; Carrieri, De Paola et al., 2020). We do not use these data as the exposure relates to disease more generally and the nature of occupations may differ between Ireland and the US. We instead use mortality information from England and Wales. The Office for National 
Statistics (ONS) publishes data from England and Wales on COVID-19 mortality by occupation, using SOC2010 categorisation. While the statistics do not directly relate to Ireland, they may generalise to Ireland and other European countries, and therefore may help inform policy. These data are at a four-digit SOC level.

In Table 5 we show the 10 occupations that accounted for the highest share of overall COVID-19 deaths in the working-age population in England and Wales ${ }^{5}$ alongside our measures of risk for Ireland. We highlight for each occupation in Ireland if they were above the average for all workers (cells highlighted in red), and if they were occupations found in Table 2-4 to have high risk of severe COVID-19 outcomes (occupation highlighted in bold).

Column I of Table 5 shows that, overall, these 10 occupations accounted for over 27 per cent of COVID-19 deaths among those aged 20-64 in England and Wales. Care workers and home carers, taxi drivers, security guards and sales assistants accounted for 5.3, 4.2, 3.5 and 2.8 per cent, respectively, of all COVID-19 deaths among those aged 20-64 in England and Wales. The share of deaths is also disproportionate to their workforce share. Despite carers, taxi drivers and security guards accounting for only 3.6 per cent of the workforce in England and Wales, they account for 13 per cent of COVID-19 deaths in the working-age population (ONS, 2020; Williams, 2020).

Results in columns II-IV show that many of those occupations found to have high mortality in England and Wales have risks above average across the three risk dimensions studied in this piece. Six of the 10 occupations shown (highlighted in bold) have been shown in Tables 2-4 to have high risk across at least two risk dimensions. Therefore, in addition to facing a higher risk of contracting the illness due to greater exposure, particularly among care workers and taxi drivers (due to the nature of their work), our analysis shows that these occupations also face a greater risk of negative outcomes due to prevailing health conditions. Nine out of the 10 occupations in Table 5 are shown to comprise workers who live in areas of higher deprivation in Ireland.

Some occupations found to have high risk profiles in Tables 2-4 do not appear in Table 5 as they have not experienced high rates of mortality in England and Wales. Possible explanations for this include that they are not essential workers or are able to work from home, or that they are less exposed to the virus. For example, despite agricultural and related trades (e.g. farmers) having high risk profiles across each dimension, due to the nature of their work and the closure/modifications of

\footnotetext{
${ }^{5}$ ONS results reflect deaths among those aged 20-64, while results from Ireland in this analysis reflect workers aged $15+$ years. However, 92 per cent of workers aged 15+ years in Ireland fall into the 20-64 years age bracket. Therefore, our samples, while not identical, are comparable.
} 
some agricultural activities such as marts, they may have lower exposure and therefore lower probability of severe outcomes.

TABLE 5 OCCUPATIONS IDENTIFIED TO BE AT HIGHEST RISK FROM COVID-19

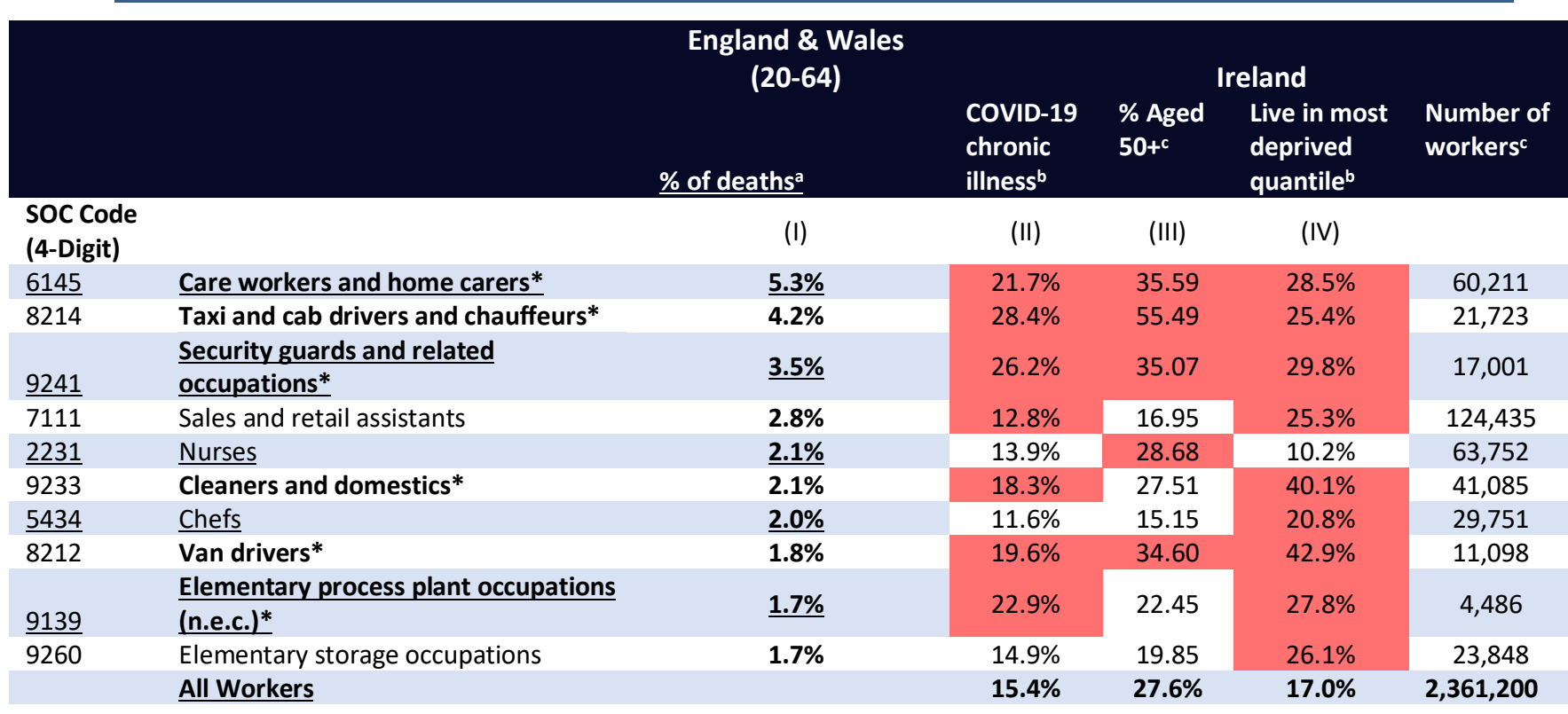

Sources: $\quad{ }^{a}$ Office for National Statistics; ${ }^{b}$ Healthy Ireland Survey (Waves 1-4); ${ }^{c}$ Labour Force Survey: Numbers of workers estimated for quarter 4 of 2019.

Notes: $\quad$ Bold occupations are high-risk across at least two risk dimensions in Tables 2-4. Red cells denote above-average risk. 


\section{CONCLUSION}

This study finds large differences in the potential risk of severe outcome from COVID-19 due to workers' underlying characteristics across occupations. We find that many of those occupations seen as essential by the Government to ensure the running of society and the economy at the onset of the COVID-19 pandemic have among the highest risk factors for severe outcomes due to COVID-19 (e.g. hospitalisation and death) in Ireland. Many of these occupations score highly across each of the risk dimensions measured. In addition, mortality data from England and Wales show a relationship between those occupations with higher risk profiles and higher mortality rates from the disease.

While we cannot draw a causal relationship between risk profiles and mortality from our results, they nevertheless suggest that particular consideration should be given to how infection risk can be mitigated in certain occupations. For example, this could include ensuring that carers receive adequate PPE when working both in private homes and residential facilities, or requiring barriers, screens and contactless payments to reduce the risk of taxi, bus and coach drivers being infected by passengers.

While we have highlighted some at-risk occupations and suggested some relatively simple policy solutions, policymakers in conjunction with private-sector industry should be focused on designing and implementing innovative strategies to protect workers who are at a high risk of contracting, and dying from, COVID-19. Although a comprehensive analysis of the types of policies and interventions that could be considered is beyond the scope of this paper, the analysis presented here could help policymakers identify the occupations that require the greatest policy focus. In the Return to Work Safely Protocol, it is noted that we are dealing with a 'rapidly moving challenge'; as new evidence and information emerge, the Protocol will likely be supplemented by further guidance.

In particular, the results from Table 5 may help in targeting workers who have been found to be most at risk from COVID-19, both in terms of contracting the illness and experiencing severe outcomes. Two groups of workers that we know have been disproportionately affected by COVID-19 in Ireland are healthcare workers and process plant workers. Our results suggest that treating healthcare workers as one homogenous group of workers may be misplaced. Job roles, patient interaction and workplace characteristics differ across 'healthcare workers'; so too does their risk profile. Carers in particular have high rates of underlying health conditions, are older, and are more likely to live in more deprived areas. This group 
has also seen the largest mortality rate in England and Wales. Therefore, ensuring that these workers have access to protection, such as PPE, is imperative.

As of 6 June, there were 1,048 confirmed cases among workers in meat processing plants, and 27 hospitalisations. ${ }^{6}$ The high rates in this sector led to the HSE issuing guidance to meat factory workers on controlling outbreaks (HSE, 2020). For elementary processing plant workers more generally, we find that, despite having a younger age profile (only $17 \%$ were aged 50 years and older), they have high risk to COVID-19 based on their COVID-19-vulnerable chronic illness rates (19\%) and living in more deprived areas. This puts them at high risk to both exposure and severe outcomes.

Table 5 also highlights other high-risk workers for whom targeted policies may help to mitigate risk. The Return to Work Safely Protocol advises that at-risk workers work from home where possible, and that, if they cannot, they should be supported to maintain a two-metre physical distance in the workplace. In addition, other measures that could be considered are moving workers to tasks with lower potential exposure to COVID-19. Taxi drivers (a subgroup of road transport drivers) are constantly interacting with the public throughout the course of their day, increasing their risk of contracting the virus. We also know that taxi drivers have high rates of other chronic illnesses, and have been shown to have a high mortality risk from COVID-19 in England and Wales. Therefore, policies could be implemented to ensure that taxi drivers are protected to a reasonable degree. This could include perspex barriers to separate the driver from the passenger, which are already included in some taxis, along with card-only payments. Such measures can be expanded to other road passenger transport drivers also.

Not all workers who have continued working through the pandemic have seen large increases in COVID-19, despite having higher risk profiles. This could be explained by low exposure to COVID-19 due to the nature of their jobs. Many agricultural workers such as farmers continued to work, but no evidence has been released showing high rates of COVID-19 in this group. However, due to the chronic illness rates and age (and age of household - see Table A1), they do have higher risk from COVID-19. Reducing risk of infection from larger gatherings in marts or food/animal fairs should be considered if rates of COVID-19 in the community are high, or if clusters appear in specific localities. Results also point to other occupations at higher risk, such as housekeepers, and who may be returning to workplaces as we enter the phased reopening of the economy.

Due to data limitations and the relatively short period over which COVID-19 has

\footnotetext{
${ }^{6}$ www. irishtimes.com/news/health/safety-watchdog-has-inspected-13-meat-plants-with-covid-19outbreaks-1.4272047
} 
occurred, there are likely to be other risk dimensions not captured in this work. For example, measured exposure to the disease, availability of PPE, use of private versus public transport, and living in overcrowded housing are all likely to be important risk dimensions, and differ across occupations. Evidence from other countries has also shown large differences in COVID-19 infection rates and severe outcomes across race and ethnicities (ONS 2020), though some of these differences have been shown to be explained by socio-economic/deprivation factors (Public Health England 2020). While there is little evidence to date of race, ethnicity or nationality and COVID-19 risk in Ireland, migrant workers may be more at risk due to lower dissemination of public health advice or probability of living in more overcrowded homes. Therefore, the fact that 31 per cent of elementary process plant workers and 21 per cent of care workers (estimates from HIS) were born outside Ireland may explain some of the higher risk in these groups. There are large differences in COVID-19 confirmed case rates across regions in Ireland. Dublin and the Mid-East, as well as more urban areas, have had the highest rates of COVID-19. As occupations differ according to region and between rural and urban areas, more localised policies to mitigate risk in the workplace, especially when clusters appear, may be appropriate.

In conclusion, the COVID-19 crisis has shown in greater detail differences in health status and the socio-economic disparities that exist between occupations in Ireland. This study has found that often it is those occupations most essential to the running of society and the economy that have the highest risk of severe outcomes if COVID-19 is contracted. Yet these workers have been at the frontline of the COVID-19 crisis - a frontline that spans both healthcare and non-healthcare workers. These occupations tend to have workers who are in lower-paying and less secure professions. Policies to ensure adequate protection of these workers is needed. Improved data to understand the occupational exposure to COVID-19, including the occupations that are most exposed to the illness, will allow for 'upstream prevention measures' in the workplace (e.g. distancing) and employment regulation (e.g. sick leave) (Baker, Peckham et al., 2020). Finally, if COVID-19 infection rates remain low in Ireland, fewer policies will be required in the workplace to guard against infection. However, these data will be of importance for policymakers if faced with a second wave of COVID-19 in the coming months. 



\section{REFERENCES}

Baker, M. G., T. K. Peckham and N. S. Seixas (2020). 'Estimating the burden of United States workers exposed to infection or disease: A key factor in containing risk of COVID19 infection', PLOS ONE 15(4): e0232452.

Carrieri, V., M. De Paola and F. Gioia (2020). 'The impact of communication on preferences for public policies: Evidence from a field experiment on the Covid-19 health-wealth trade-off', CEPR Covid Economics Vetted and Real-Time Papers 25.

Crowley, F. and J. Doran (2020). 'Covid-19, Occupational Social Distancing and Remote Working Potential in Ireland', University College Cork.

CSO (2020a). Occupations with Potential Exposure to COVID-19. Central Statistics Office.

CSO (2020b). COVID-19 Deaths and Cases: From 28 February to 15 May 2020. Central Statistics Office.

Department of Business, E. \& I. (2020). Return to Work Safely Protocol, COVID-19 Specific National Protocol for Employers and Workers. Collaborative effort by the Health and Safety Authority (HSA), the Department of Health, and the Department of Business, Enterprise and Innovation.

Department of the Taoiseach (2020). 'List of essential service providers under new public health guidelines'. Retrieved 04/06/2020, from

www.gov.ie/en/publication/dfeb8f-list-of-essential-service-providers-under-newpublic-health-guidelin/.

ECDC (2020). 'Coronavirus disease 2019 (COVID-19) pandemic: increased transmission in the EU/EEA and the UK - seventh update', European Centre for Disease Prevention and Control. Stockholm.

Farquharson, C., I. Rasul and L. Sibieta (2020). 'Key workers: key facts and questions', IFS Briefing Note BN 285.

Hennelly, N. and S. Cahill (2020). 'New report: The impact of COVID-19 pandemic on people living with dementia in Ireland', International Long-Term Care Policy Network, CPEC-LSE.

Hernández, B., D. Sexton, F. Moriarty, N. Cosgrave, A. O'Halloran, C. McGarrigle, S. Scarlett and R. A. Kenny (2020). 'High-risk categories for COVID-19 and their distribution by county in Republic of Ireland -- Evidence from the TILDA study'. TILDA.

HPSC (2020a). 'Report of the profile of COVID-19 cases in healthcare workers in Ireland', Health Protection Surveillance Centre.

HPSC (2020b). 'Underlying conditions in confirmed cases of COVID-19 in Ireland', Health Protection Surveillance Centre.

HSE (2020). 'COVID-19 Outbreaks in Meat Factories in Ireland Outbreak Control Team', Interim Guidance on COVID-19. V1.0. Health Service Executive.

Ji, Y., Z. Ma, M. P. Peppelenbosch and Q. Pan (2020). 'Potential association between COVID19 mortality and health-care resource availability', The Lancet Global Health 8(4): e480. 
ONS (2020). 'Coronavirus (COVID-19) related deaths by occupation, England and Wales: deaths registered up to and including 20 April 2020', Office for National Statistics.

ONS (2020). 'Deaths involving COVID-19 by local area and deprivation', Office for National Statistics.

ONS (2020). 'Deaths involving COVID-19, England and Wales: deaths occurring in April 2020 ', Office for National Statistics.

Public Health England (2020). 'COVID-19: review of disparities in risks and outcomes', Public Health England.

Redmond, P. and S. McGuinness (2020). 'Who can work from home in Ireland?' ESRI Survey and Statistical Report Series 87.

Roe, L., C. Normand, M.-A. Wren, J. Browne and A. M. O'Halloran (2017). 'The impact of frailty on healthcare utilisation in Ireland: evidence from the Irish longitudinal study on ageing', BMC Geriatrics 17(1): 203.

Williams, M. (2020). 'Coronavirus class divide - the jobs most at risk of contracting and dying from COVID-19', The Conversation. 


\section{APPENDIX}

TABLE A1 OCCUPATIONS BY RISK DIMENSION

\begin{tabular}{|c|c|c|c|c|c|}
\hline SOC 2010 Code & Occupation & $\begin{array}{c}\text { COVID- } \\
19 \\
\text { chronic } \\
\text { illness }^{\mathrm{a}} \\
\end{array}$ & $\begin{array}{c}\% \\
\text { Aged } \\
50++^{b}\end{array}$ & $\begin{array}{c}\text { Live in } \\
\text { most } \\
\text { deprived } \\
\text { quantile }^{\mathrm{a}}\end{array}$ & $\begin{array}{c}\text { Number } \\
\text { of } \\
\text { workers }^{b}\end{array}$ \\
\hline 111 & Chief Executives \& Senior Officials & $*$ & $51.52 \%$ & $*$ & 5,074 \\
\hline 112 & Production Managers \& Directors & $16.10 \%$ & $33.62 \%$ & $6.40 \%$ & 25,769 \\
\hline 113 & Functional Managers \& Directors & $10.70 \%$ & $37.60 \%$ & $4.99 \%$ & 53,471 \\
\hline 115 & Financial Institution Managers \& Directors & $22.20 \%$ & $30.61 \%$ & $0.00 \%$ & 7,368 \\
\hline 116 & Managers and Directors in Transport \& Logistics & $24.20 \%$ & $34.42 \%$ & $3.89 \%$ & 10,373 \\
\hline 117 & Senior Officers in Protective Services & $*$ & $*$ & $0.00 \%$ & $*$ \\
\hline 118 & Health and Social Services Managers \& Directors & $16.30 \%$ & $40.59 \%$ & $18.15 \%$ & 4,451 \\
\hline 119 & Managers and Directors in Retail \& Wholesale & $12.50 \%$ & $25.49 \%$ & $17.47 \%$ & 25,507 \\
\hline 121 & Managers and Proprietors in Agriculture Related Services & $*$ & $56.50 \%$ & $*$ & 4,987 \\
\hline 122 & Managers and Proprietors in Hospitality \& Leisure Services & $14.90 \%$ & $30.54 \%$ & $16.06 \%$ & 24,149 \\
\hline 124 & Managers and Proprietors in Health \& Care Services & * & $40.70 \%$ & $*$ & 3,029 \\
\hline 125 & Managers and Proprietors in Other Services & $16.20 \%$ & $44.56 \%$ & $8.37 \%$ & 38,598 \\
\hline 211 & Natural and Social Science Professionals & $10.10 \%$ & $14.22 \%$ & $7.51 \%$ & 14,711 \\
\hline 212 & Engineering Professionals & $7.60 \%$ & $21.89 \%$ & $3.64 \%$ & 33,623 \\
\hline 213 & Information Technology \& Telecommunications Professionals & $9.60 \%$ & $13.13 \%$ & $8.07 \%$ & 56,139 \\
\hline 214 & Conservation and Environment Profs & $*$ & $25.66 \%$ & $*$ & 2,406 \\
\hline 215 & Research and Development Managers & $*$ & $*$ & $*$ & - \\
\hline 221 & Health Professionals & $14.40 \%$ & $24.67 \%$ & $5.21 \%$ & 35,045 \\
\hline 222 & Therapy Professionals & $15.20 \%$ & $25.57 \%$ & $6.39 \%$ & 12,504 \\
\hline 223 & Nursing \& Midwifery Professionals & $13.80 \%$ & $28.73 \%$ & $10.16 \%$ & 67,160 \\
\hline 231 & Teaching \& Educational Professionals & $14.80 \%$ & $27.49 \%$ & $8.73 \%$ & 129,457 \\
\hline 241 & Legal Professionals & $7.40 \%$ & $28.82 \%$ & $5.19 \%$ & 14,499 \\
\hline 242 & Business, Research \& Administrative Profs & $12.50 \%$ & $21.22 \%$ & $6.30 \%$ & 67,297 \\
\hline 243 & Architects, Town Planners \& Surveyors & $18.10 \%$ & $21.54 \%$ & $7.82 \%$ & 14,250 \\
\hline 244 & Welfare Professionals & $11.10 \%$ & $42.63 \%$ & $17.40 \%$ & 9,101 \\
\hline 245 & Librarians \& Related Professionals & $*$ & $42.17 \%$ & $*$ & 3,042 \\
\hline 246 & Quality \& Regulatory Professionals & $18.20 \%$ & $23.09 \%$ & $9.09 \%$ & 7,617 \\
\hline 247 & Media Professionals & $15.20 \%$ & $18.08 \%$ & $0.78 \%$ & 7,331 \\
\hline 311 & Science, Engineering \& Production Technicians & $14.70 \%$ & $19.78 \%$ & $21.16 \%$ & 25,956 \\
\hline 312 & Draughtspersons \& Related Architectural Technicians & $*$ & $22.10 \%$ & $*$ & 3,391 \\
\hline 313 & Information Technology Technicians & $6.50 \%$ & $12.64 \%$ & $13.57 \%$ & 19,286 \\
\hline 321 & Health Associate Professionals & $10.50 \%$ & $32.06 \%$ & $18.50 \%$ & 11,632 \\
\hline 323 & Welfare \& Housing Associate Professionals & $18.70 \%$ & $32.12 \%$ & $24.68 \%$ & 10,846 \\
\hline 331 & Protective Service Occupations & $11.00 \%$ & $17.48 \%$ & $11.99 \%$ & 25,632 \\
\hline 341 & Artistic, Literary \& Media Occupations & $16.90 \%$ & $30.15 \%$ & $9.85 \%$ & 20,969 \\
\hline 342 & Design Occupations & $8.35 \%$ & $21.12 \%$ & $12.22 \%$ & 6,969 \\
\hline 344 & Sports and Fitness Occupations & $13.10 \%$ & $12.80 \%$ & $14.85 \%$ & 11,357 \\
\hline 351 & Transport Associate Professionals & * & $26.87 \%$ & $*$ & 2,531 \\
\hline 352 & Legal Associate Professionals & $*$ & $14.73 \%$ & $*$ & 3,266 \\
\hline 353 & Business, Finance $\&$ Related Associate Profs & $16.90 \%$ & $20.95 \%$ & $6.49 \%$ & 44,981 \\
\hline 354 & Sales, Marketing \& Related Associate Profs & $17.00 \%$ & $20.22 \%$ & $10.01 \%$ & 56,588 \\
\hline 355 & Conservation \& Environmental Associate Professionals & $*$ & $*$ & $*$ & * \\
\hline 356 & Public Services \& Other Associate Profs & $20.40 \%$ & $33.61 \%$ & $14.73 \%$ & 30,931 \\
\hline 411 & Administrative Occs.: Gov \& Related Orgs & $16.20 \%$ & $40.13 \%$ & $13.93 \%$ & 51,277 \\
\hline 412 & Administrative Occupations: Finance & $16.30 \%$ & $27.75 \%$ & $14.72 \%$ & 55,316 \\
\hline 413 & Administrative Occupations: Records & $16.50 \%$ & $21.55 \%$ & $12.81 \%$ & 18,551 \\
\hline 415 & Other Administrative Occupations & $14.70 \%$ & $31.07 \%$ & $15.94 \%$ & 63,993 \\
\hline 416 & Administrative Occupations: Office Managers and Supervisors & $10.30 \%$ & $34.91 \%$ & $19.29 \%$ & 10,397 \\
\hline 421 & Secretarial \& Related Occupations & $15.10 \%$ & $38.42 \%$ & $15.39 \%$ & 48,247 \\
\hline 511 & Agricultural \& Related Trades & $19.50 \%$ & $62.81 \%$ & $12.33 \%$ & 110,233 \\
\hline
\end{tabular}




\begin{tabular}{|c|c|c|c|c|c|}
\hline 521 & Metal Forming, Welding \& Related Trades & $18.00 \%$ & $24.33 \%$ & $19.40 \%$ & 11,981 \\
\hline 522 & Metal Machining, Fitting \& Instrument Making Trades & $13.40 \%$ & $27.54 \%$ & $8.37 \%$ & 20,932 \\
\hline 523 & Vehicle Trades & $14.10 \%$ & $23.47 \%$ & $17.75 \%$ & 21,094 \\
\hline 524 & Electrical \& Electronic Trades & $13.80 \%$ & $23.65 \%$ & $16.27 \%$ & 39,321 \\
\hline 525 & Skilled Metal, Electrical \& Electronic Trades Supervisors & $*$ & * & $*$ & * \\
\hline 531 & Construction \& Building Trades & $12.00 \%$ & $27.50 \%$ & $15.06 \%$ & 57,785 \\
\hline 532 & Building Finishing Trades & $15.80 \%$ & $29.18 \%$ & $20.87 \%$ & 18,688 \\
\hline 533 & Construction \& Building Trades Supervisors & $*$ & $32.49 \%$ & $*$ & 4,301 \\
\hline 541 & Textiles \& Garments Trades & $*$ & $*$ & $*$ & $*$ \\
\hline 542 & Printing Trades & $*$ & $25.01 \%$ & $*$ & 2,793 \\
\hline 543 & Food Preparation \& Hospitality Trades & $17.30 \%$ & $20.72 \%$ & $21.90 \%$ & 48,260 \\
\hline 544 & Other Skilled Trades & $22.60 \%$ & $32.89 \%$ & $13.40 \%$ & 7,929 \\
\hline 612 & Childcare \& Related Personal Services & $14.30 \%$ & $29.21 \%$ & $20.51 \%$ & 50,803 \\
\hline 613 & Animal Care \& Control Services & $16.10 \%$ & $21.27 \%$ & $11.29 \%$ & 4,713 \\
\hline 614 & Caring Personal Services & $22.00 \%$ & $34.32 \%$ & $27.69 \%$ & 84,801 \\
\hline 621 & Leisure \& Travel Services & $14.50 \%$ & $18.79 \%$ & $18.71 \%$ & 12,504 \\
\hline 622 & Hairdressers \& Related Services & $8.30 \%$ & $9.11 \%$ & $19.26 \%$ & 26,854 \\
\hline 623 & Housekeeping \& Related Services & $33.90 \%$ & $52.60 \%$ & $26.99 \%$ & 19,810 \\
\hline 624 & Cleaning and Housekeeping Managers \& Supervisors & $*$ & $*$ & $*$ & $*$ \\
\hline 711 & Sales Assistants \& Retail Cashiers & $12.90 \%$ & $17.03 \%$ & $23.89 \%$ & 138,159 \\
\hline 712 & Sales Related Occupations & $15.60 \%$ & $25.13 \%$ & $11.31 \%$ & 17,541 \\
\hline 713 & Sales Supervisors & $*$ & $11.91 \%$ & $*$ & 5,810 \\
\hline 721 & Customer Service Occupations & $8.30 \%$ & $9.99 \%$ & $23.48 \%$ & 21,942 \\
\hline 722 & Customer Service Managers \& Supervisors & $*$ & $13.12 \%$ & $*$ & 3,802 \\
\hline 811 & Process Operatives & $15.70 \%$ & $20.74 \%$ & $23.04 \%$ & 31,903 \\
\hline 812 & Plant \& Machine Operatives & $11.50 \%$ & $26.91 \%$ & $19.54 \%$ & 11,407 \\
\hline 813 & Assemblers \& Routine Operatives & $12.70 \%$ & $18.84 \%$ & $23.48 \%$ & 35,381 \\
\hline 814 & Construction Operatives & $14.20 \%$ & $34.98 \%$ & $28.73 \%$ & 12,205 \\
\hline 821 & Road Transport Drivers & $25.80 \%$ & $47.21 \%$ & $27.90 \%$ & 70,351 \\
\hline 822 & Mobile Machine Drivers \& Operatives & $17.50 \%$ & $26.75 \%$ & $23.87 \%$ & 16,045 \\
\hline 823 & Other Drivers \& Transport Operatives & $*$ & $34.56 \%$ & $*$ & 5,423 \\
\hline 911 & Elementary Agricultural Occupations & $14.20 \%$ & $25.53 \%$ & $7.41 \%$ & 11,532 \\
\hline 912 & Elementary Construction Occupations & $14.10 \%$ & $27.68 \%$ & $35.49 \%$ & 24,236 \\
\hline 913 & Elementary Process Plant Occupations & $19.10 \%$ & $17.27 \%$ & $24.74 \%$ & 11,395 \\
\hline 921 & Elementary Administration Occupations & $8.40 \%$ & $46.56 \%$ & $19.79 \%$ & 10,198 \\
\hline 923 & Elementary Cleaning Occupations & $18.30 \%$ & $33.14 \%$ & $39.43 \%$ & 45,529 \\
\hline 924 & Elementary Security Occupations & $23.40 \%$ & $29.15 \%$ & $29.48 \%$ & 17,878 \\
\hline 925 & Elementary Sales Occupations & $*$ & $*$ & $*$ & $*$ \\
\hline 926 & Elementary Storage Occupations & $14.90 \%$ & $19.85 \%$ & $26.12 \%$ & 22,615 \\
\hline \multirow[t]{2}{*}{927} & Other Elementary Services Occupations & $15.40 \%$ & $12.01 \%$ & $23.80 \%$ & 95,622 \\
\hline & All Workers & & & & $2,361,200$ \\
\hline
\end{tabular}

Sources: a Healthy Ireland Survey (Waves 1-4); ${ }^{\mathrm{b}}$ Labour Force Survey: Numbers of workers estimated for quarter 4 of 2019.

Notes: $\quad$ Red denotes higher risk on average, green denotes lower risk on average, neutral denotes average risk.

* Too few observations to be included. 
Whitaker Square,

Sir John Rogerson's Quay, Dublin 2

Telephone +35318632000

Email admin@esri.ie

Web www.esri.ie

Twitter @ESRIDublin

ISBN 978-0-7070-536-2 